\title{
CFD modelling of biomass catalytic fast pyrolysis in bubbling fluidized reactor: effects of catalyst parameters
}

\author{
Yajun Qiu ${ }^{1}$, Qixiang $\mathrm{Xu}^{2}$, Shusheng $\mathrm{Pang}^{3}$, and Xiaoyuechuan $\mathrm{Ma}^{2}$ \\ ${ }^{1}$ Patent Examination Cooperation (Henan) Center of the Patent Office \\ 2Zhengzhou University \\ ${ }^{3}$ University of Canterbury
}

September 25, 2021

\begin{abstract}
In this study, a CFD mathematical model has been developed for catalytic fast pyrolysis (CFP) of biomass. The multi-phase fluid flow, and the inter-phase momentum and energy transfer processes were modelled with Eulerian multi-phase formulas. The biomass catalyst fast pyrolysis reactions were described by using a two-stage, semi-global model. Specified secondary tar catalytic cracking process, which considers both intrinsic reaction rates and mass transfer process are embedded to the developed model by user-defined function (UDF). The developed model has then been employed to investigate the effects of structural properties of catalyst, such as specific internal area, average size of active sites, pore diameter, and tortuosity, on products yields and composition. The influences of adsorption capability of tar molecule on catalyst surface and external film mass transfer were also analyzed. The developed model can be employed for further research and engineering designs of the catalyst pyrolysis of carbonaceous materials.
\end{abstract}

\section{Hosted file}

CFD modelling of CFP.docx available at https://authorea.com/users/437278/articles/539028cfd-modelling-of-biomass-catalytic-fast-pyrolysis-in-bubbling-fluidized-reactor-effectsof-catalyst-parameters 